\title{
Estimation of Hurst exponent of seismic signal
}

\section{N. Sychev}

S. A. Imashev
Research Station of Russian Academy of Sciences in Bishkek, Kyrgyzstan

\begin{abstract}
A review of main methods of Hurst exponent estimation for study of fractal properties of time series is carried out. The following methods gave the most accurate estimates of Hurst parameter in a wide range of values and lengths of signals - DFA, WDSOD and AWC in case of continuous transform with Morlet wavelet. On the basis of fractal analysis of seismic noise we revealed that it is characterized by multifractality. Changes in fractal properties of the signal can be used to determine the seismic wave arrival time. Hurst parameter of high-frequency seismic noise showed changes in values and fluctuation range during the seismic event.
\end{abstract}

\section{Keywords}

Fractal analysis, Wavelet analysis, Fractal dimension, Hurst parameter, Seismic signal

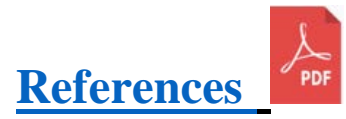

For citation: Sychev V.N., Imashev S.A. Estimation of Hurst exponent of seismic signal. Geosystems of Transition Zones, 2017, vol. 1, N 2, p. 50-61. doi:10.30730/2541-8912.2017.1.2.050-061 